\title{
Aspects of aero-engine nacelle drag
}

\author{
Matthew Robinson ${ }^{1}$, David G. MacManus ${ }^{2}$ \\ Cranfield University, Bedfordshire, United Kingdom, MK43 OAL
}

\author{
Christopher Sheaf ${ }^{3}$ \\ Rolls-Royce plc, P.O Box 31 \\ Derby, United Kingdom, DE24 8BJ
}

\begin{abstract}
To address the need for accurate nacelle drag estimation, an assessment has been made of different nacelle configurations used for drag evaluation. These include a sting mounted nacelle, a nacelle in free flow with an idealised, freestream pressure matched, efflux and a nacelle with a full exhaust system and representative nozzle pressure ratio. An aerodynamic analysis using numerical methods has been carried out on four nacelles to assess a near field drag extraction method using computational fluid dynamics. The nacelles were modelled at a range of aerodynamic conditions and three were compared against wind tunnel data. A comparison is made between the drag extraction methods used in the wind tunnel analysis and the chosen computational fluid dynamics approach which utilised the modified near field method for evaluation of drag coefficients and trends with Mach number and mass flow. The effect of sting mounting is quantified and its influence on the drag measured by the wind tunnel methodology determined. This highlights notably differences in the rate of change of drag with free stream Mach number, and also the flow over the nacelle. A post exit stream tube was also found to create a large additional interference term acting on the nacelle. This term typically accounts for $50 \%$ of the modified nacelle drag and its inclusion increased the drag rise Mach number by around $\Delta M=0.026$ from $M=0.849$ to $M=$ 0.875 for the examples considered.
\end{abstract}

\section{${ }^{1}$ Corresponding Author:}

Matthew Robinson, PhD Student Researcher, Centre for Propulsion, Cranfield University,

Email: matthew.robinson@cranfield.ac.uk

${ }^{2}$ Head of Gas Turbine Technology Group, Propulsion Engineering Centre, Cranfield University

${ }^{3}$ Installation Aerodynamics specialist 


\section{Nomenclature}

\section{Abbreviations}

AGARD Advisory Group for Aerospace Research and Development

ARA

Aircraft Research Association

BPR

By Pass Ratio

CFD

Computational Fluid Dynamics

CFL

Courant-Friedrich-Lewy

DPW

Drag Prediction Workshop

ELFIN

European Laminar Flow Investigation

GCI

Grid convergence index

ISA

International standard atmosphere

LARA Laminar flow Research Action

MFCR Mass flow capture ratio

MS/FS Model scale/Full scale

$\mathrm{N}$

Nacelle configuration

NE

Nacelle/exhaust configuration

NS

Nacelle/sting configuration

NACA

National Advisory Council for Aeronautics

NASA

National Aeronautics and Space Administration

NLF

Natural Laminar Flow

$\mathrm{PM} / \mathrm{RE}$

Pressure matched/Realistic efflux boundary conditions

RANS

Reynolds-averaged Navier-Stokes

RMS

Root mean squared

SST

Shear stress transport

UHBPR

Ultra-High By-pass ratio

Symbols

A

$\mathrm{c}_{\mathrm{D}}$

$\mathrm{c}_{\mathrm{f}}$

$\mathrm{c}_{\mathrm{p}}$

d

D

F

k

L

$\dot{m}$

M

$\mathrm{n}$

$\mathrm{P}$

r

Re
Area

Nacelle drag coefficient

Skin friction coefficient

Pressure coefficient

Diameter

Nacelle drag force

Force

Turbulent kinetic energy

Length

Mass flow rate

Mach number

Unit normal

Total pressure

Radius

Reynolds number $\left[\mathrm{m}^{2}\right]$

[-]

[-]

[-]

[m]

[N]

[N]

[ $\left.\mathrm{Jkg}^{-1}\right]$

[m]

$\left[\mathrm{kg} \mathrm{s}^{-1}\right]$

[-]

[-]

[Pa]

[m]

[-] 


$\begin{array}{ll}\text { Rex } & \text { Reynolds number per unit length } \\ \text { V } & \text { Velocity } \\ {[\mathrm{x}, \mathrm{y}, \mathrm{z}]} & \text { Cartesian coordinates } \\ \alpha & \text { Incidence } \\ \beta & \text { Boat tail angle } \\ \rho & \text { Density } \\ \tau & \text { Shear stress } \\ \phi & \text { Force } \\ \omega & \text { Specific rate of dissipation } \\ \text { Subscripts } & \\ \mathrm{a} & \text { Afterbody } \\ \mathrm{c} & \text { Centrebody } \\ \text { combined } & \text { Nacelle and sting combined } \\ \text { CL } & \text { Centre line } \\ \text { DR } & \text { Drag rise } \\ \mathrm{e} & \text { Exit } \\ \mathrm{f} & \text { Forebody } \\ \text { i } & \text { Highlight } \\ \text { if } & \text { Initial forebody } \\ \text { interf } & \text { Interference } \\ \mathrm{m} & \text { Maximum } \\ \text { nac } & \text { Nacelle } \\ \text { pre } & \text { Pre-entry } \\ \text { sting } & \text { Sting section upstream of measurement plane } \\ \mathrm{t} & \text { Total } \\ \text { wc } & \text { Wetted cowl } \\ \text { ws } & \text { Wetted sting upstream of measurement plane } \\ 0 & \text { Upstream infinity station } \\ \infty & \text { Freestream } \\ * & \text { Modified } \\ & \end{array}$




\section{Introduction}

There is an ongoing need to improve aircraft performance to reduce fuel burn, emissions and operating costs [1, 2]. Improvement in engine technologies is needed to provide a significant part of the fuel burn reduction [2]. In recent decades, the on-going development of the aero-engine has followed a trend of increasing the bypass ratio (BPR) of a turbofan engine in order to improve its propulsive efficiency [3]. As the bypass ratio has increased, the fan diameter has grown substantially; whilst the core size has reduced relatively. Although the increase in fan diameter provides benefits to the uninstalled engine cycle, there are adverse effects due to nacelle drag, weight and installation difficulties that offset some of the cycle benefits. Therefore, as this trend for increasing fan diameter continues, it is important to reduce the drag penalty from a larger engine to allow improvements in overall aircraft fuel burn.

A notable contributor to the drag of a modern aero-engine comes from the nacelle [4] [5]. The nacelle is optimised to balance the requirement to contribute as little drag as possible to the overall installation; while providing the quantity and quality of flow required by the engine and incorporating an exhaust system which satisfies cycle compatibility, efficiency, and noise suppression requirements over the full aircraft flight envelope [6]. As jet engines have increased in size, the nacelle design has become more critical. A previous study reported an overall engine installation contribution of around $14 \%$ of the drag for a civil twin-engine airliner [4], and an increase in diameter will cause greater nacelle drag and interference with the wing [5]. Significant work has been carried out to try to understand and mitigate the impact of large engines on the overall performance of aircraft. A study into the overall system performance of high BPR engine designs up to a BPR of 21.5 looked at improving three baseline engines and found that increases in fan diameter from $2.85 \mathrm{~m}$ to $3.25 \mathrm{~m}$, with a BPR increase from 6.2 to 14.3 , could provide improvements in overall fuel burn of $15-16 \%$ for an engine with a thrust class in the range of 350-390 kN [7]. However this study did not look at the detailed aerodynamic design of the nacelles or the interaction with the wing. Another assessment of 'advanced' engine and nacelle concepts looked to apply slimmer and shorter nacelles to engines in the thrust class range of $107-267 \mathrm{kN}$. These engines incorporated novel nacelles for engines with geared cycles and demonstrated that with an optimal nacelle design, savings of $3 \%$ in fuel burn were possible from the advanced nacelle design for a large twin engine aircraft [8]. The Common Research Model (CRM) is an aircraft configuration comprising wing/body/nacelle/pylon/horizontal-tail [9]. It was developed as a model for wind tunnel and Computational Fluid Dynamics (CFD) analysis to be used to predict drag characteristics of modern wide body civil aircraft [9]. Principal experimental data for the CRM comes from the NASA Ames 11-ft wind tunnel and the NASA Langley National Transonic Facility [10]. The impact of the through-flow nacelle and pylon were seen to cause an increase in drag of around 20 drag counts, approximately $10 \%$ of overall aircraft drag, at the cruise Mach number of 0.85 and lift coefficient of 0.5. As engines increase in size, these influences on drag are expected to become more important and nacelle design will become of increasing importance. Consequently, there is a need to establish the required experimental and computational tools to enable the reliable evaluation of the nacelle performance. This includes aspects such as drag, critical drag-rise Mach number as well as spillage drag.

\section{A. Nacelle design}

A conventionally designed supercritical nacelle is characterised by a curvature driven acceleration over the forebody followed by constant deceleration [11]. For nacelles designed in this way, the peak Mach number reached in the initial acceleration is minimised. A nacelle in a transonic airflow will experience local regions of supersonic flow which typically 
terminate in shock waves and contribute to the nacelle drag. As the freestream Mach number is increased, the peak local Mach number on the nacelle increases, which results in stronger shocks and the associated wave drag penalties.

Although the design point condition is of vital importance, the off-design aspects are also crucial such as the nacelle performance at higher than cruise Mach numbers. The Mach number at which a rapid increase in drag with freestream Mach number arises is termed the drag rise Mach number and is often defined based on a drag gradient criterion as a function of the freestream Mach number. Though criteria for nacelles are not found in the published literature, several cases for full aircraft drag rise are available. For example, Roskam [12] defines the drag rise Mach number $\left(\mathrm{M}_{\mathrm{DR}}\right)$ based on a drag gradient (equation 1). The level of the criterion varies and Shevell [13] reports a value of 0.05 based on the same gradient. Roskam also discusses an alternative to the gradient based criteria as an increase of 0.002 in $c_{D}$ above the incompressible level. $\mathrm{M}_{\mathrm{DR}}$ is a key parameter for the assessment of nacelle configurations as a designer will tend to avoid being within 0.02 of the drag rise during cruise [14].

$$
\left.\frac{\partial C_{D}}{\partial M_{\infty}}\right|_{\mathrm{M}=\mathrm{M}_{\mathrm{DR}}}=0.1
$$

The streamtube (Figure 1) which enters an aero-engine varies with the aerodynamic conditions and the engine mass flow requirement. Mass flow capture ratio (MFCR) is the ratio of the cross sectional area of this streamtube at upstream infinity divided by the highlight plane area (equation 2). An engine intake is sized for the maximum required mass flow for takeoff and climb, so usually operates at a MFCR $<1$ during the cruise.

$$
\operatorname{MFCR}=\frac{A_{\infty}}{A_{i}}
$$

Spillage drag has been defined as drag incurred when the value of MFCR falls below 1 if the force which acts on the pre entry streamtube is not balanced by the forebody suction [15]. This is a particular challenge at low engine power settings. The forebody of a nacelle is required to maintain sufficient suction to compensate for the change in momentum of the streamtube between the freestream and the highlight plane. If this is not achieved, then the nacelle is considered to have spillage drag [16]. In off-design conditions, such as end of cruise where the engine is throttled back or under wind-milling conditions, the MFCR can be reduced significantly. For example a typical mid-cruise MFCR for a subsonic aircraft is in the region of 0.7 [17] which may be reduced throughout the cruise due to the mass loss of the overall aircraft. Under the critical wind-milling condition, typically considered during take-off, the MFCR may be reduced as low as 0.3 [18]. It is important for engine designers to reduce the drag penalty associated with these operating regimes. For engines of large diameters the wind-mill drag can create an excessive yaw moment resulting in the need for a larger vertical stabiliser. For instance, one study [7] identified that an increase in fan diameter from $2.84 \mathrm{~m}$ to $3.78 \mathrm{~m}$ on the B777-200ER at M=0.2, similar to a take-off condition, resulted in an increase of wind-mill drag of over $150 \%$ and an increase in the tail size of $15 \%$ was required to balance this yaw moment.

The development of nacelle forebodies began with the requirement for an aerodynamic shape for use as a cowl which did not generate excessive drag. Initial wind tunnel experiments investigated the NACA A, B and C cowls which were designed to give a high critical Mach number [19]. The NACA 1-series ordinates were developed from these initial tests [20] to provide higher critical Mach numbers and to allow operation at higher freestream Mach numbers for a greater 
range of cowl dimensions. These ordinates can then be scaled by the required nacelle proportions, $d_{m}, d_{i}$ and $L_{f}($ Figure 1$)$ to provide suitable supercritical cowl designs. As the required dimensions and operating conditions expanded for turbofan engines more complex designs have been developed [21]. Many subsequent designs were focused on improving the off design characteristics of nacelles by increasing the lip radius and thereby decreasing curvatures and accelerations over the forebody [16]. An alternative approach to nacelle design has been to maintain laminar flow over as much of the nacelle as possible, resulting in a lower skin friction drag. This approach has led to, for example, the European Laminar Flow Investigation II (ELFIN II) and Laminar flow Research Action (LARA) projects to develop laminar flow nacelles with transition positions at positions further downstream on the nacelle [22]. For example, an analysis of natural laminar flow (NLF) nacelles, with transition at $40 \%$ chord, used to power a twin-engine aircraft with a $2000 \mathrm{~nm}$ mission demonstrated potential fuel burn reductions of $1.7 \%$ [23].

Historically, the principle method to assess the drag of a nacelle has been through wind tunnel testing. For civil aeroengine configurations, this has typically been performed using a sting mounted nacelle with a suck down configuration to enable that the effects of MFCR, freestream Mach number, and incidence on the nacelle drag to be measured [21] [24] [16]. This usually allows for an assessment of a nacelle design in terms of an absolute drag value and trends in terms of transonic drag rise and spillage [21] [16] [25]. To assess the performance of a nacelle design in a wind tunnel a method is needed to quantify the drag. Strain-gauges are sometimes used to measure forces which act on a wind tunnel model but due to the order of magnitude of the drag, which is much smaller than the overall streamtube forces, it can be difficult to determine accurately. This is partially as a consequence of the sting on which the nacelle is mounted [26] and the need to vary the intake massflow. A commonly used alternative is therefore the wake integral method [25]. This directly quantifies the momentum loss caused by the model through Pitot-static measurements taken with a rake positioned in the nacelle wake.

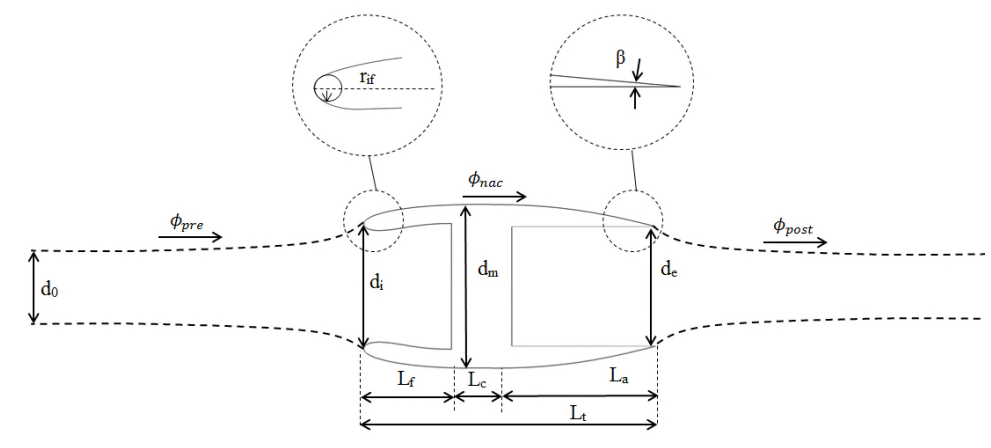

Figure 1 Nacelle geometry parameterisation based on ESDU [27] and pre-entry and post exit streamtubes

The nacelle parameterisation which will be used in this report is defined based on the established ESDU approach for nacelle design (Figure 1) [27]. Key parameters in nacelle design include the highlight diameter $\left(\mathrm{d}_{\mathrm{i}}\right)$, which directly determines the highlight area and thus the MFCR for a given intake mass flow and freestream aerodynamic condition. The maximum diameter $\left(\mathrm{d}_{\mathrm{m}}\right)$ determines the frontal facing area of the nacelle. $\mathrm{L}_{\mathrm{f}}$ is the forebody length and the combination of $\mathrm{d}_{\mathrm{m}}$ and $\mathrm{L}_{\mathrm{f}}$ are chosen to allow a favourable curvature distribution and thus $\mathrm{c}_{\mathrm{p}}$ distribution over the forebody. This requires a certain amount of initial forebody curvature, $\frac{1}{r_{i f}}$, to control the acceleration over the forebody as much as possible. Some older nacelles have a cylindrical centrebody of length $\mathrm{L}_{\mathrm{c}}$, which allows a separation distance between the forebody and afterbody geometries and reduces the interactions between the aerodynamics of these two sections. Exit diameter $\left(D_{e}\right)$ is dictated by the requirement of the engine design to achieve the cycle design point and optimised for 
efficiency and operability. The distance $\mathrm{L}_{\mathrm{a}}$ gives the distance from the maximum diameter to the trailing edge and must be of sufficient length to allow the gradient to transition smoothly from zero at the maximum radius to the required boattail angle $(\beta) . L_{t}$ is then the overall length of the nacelle and, to reduce skin friction drag, should be minimised as far as possible.

The main aim of this paper is to investigate the characteristics of aero-engine nacelle drag, to assess the impact of experimental approaches and to quantify the differences between a wind tunnel analysis of a nacelle and a CFD analysis. From this, the paper highlights the key factors of nacelle performance modelling. The work initially addresses the discretisation accuracy of the wake integral drag extraction method and goes on to use a near field method to determine the nacelle drag, drag rise and spillage. The interaction terms are directly quantified and their relative size and influence on the wind tunnel measurements is described. The discussion section explores the impact of the experimental method, the effects of the wind tunnel sting mounting and the influence of post exit stream tube aerodynamics. Overall, this work identifies and quantifies some fundamental influences with regards to nacelle aerodynamic testing. It can be used to provide guidance on nacelle installation considerations and instrumentation for wind tunnel testing. The work presents the validated level of fidelity for CFD analyses of nacelle key performance metrics and the associated requirements in terms of the computational models as well as the domain and discretisation needs.

\section{Methodology}

\section{A. Nacelle geometry}

Four nacelle geometries are considered in this paper. Nacelle 1 was designed to assess alternatives to the conventional NACA series 1 type forebody designs [16]. It is an axisymmetric design with a cylindrical centrebody, a simple circular arc and straight line for an afterbody. Nacelle 2 was designed to provide a specific Mach number distribution on the nacelle [28]. This approach can allow an acceptable aerodynamic performance for required dimensions through prescribed curvatures. It is also an axisymmetric design with no centrebody section and no straight line sections from the leading edge to the trailing edge. The removal of the centrebody causes the forebody flow to interact more strongly with the afterbody flow. Nacelle 3 is a three-dimensional design which incorporates both a conventional cylindrical centrebody as well as scarf and offset on the intake and nozzle [29]. Nacelle 4 was designed to represent a conventional nacelle design approach for an ultra-high bypass ratio (UHBPR) engine with a separate jet exhaust system. A UHBPR cycle was developed for an engine of $\mathrm{BPR}=17.8$ to cruise at a freestream Mach number of 0.82 and MFCR of 0.75 using a simulation tool for modelling engine thermodynamic performance, Turbomatch [30]. The in house software GEMINI was used to create a representative nacelle and separate jet exhaust geometry for this engine cycle [31]. Table 1 summarises the difference in design approaches taken in the four nacelles. Nacelle 1 is significantly longer but has proportionally less frontal facing area. Aerodynamic assessment of this wide range of geometric parameters allows a performance estimation for both conventional and newer designs. 
Table 1 Key geometric parameters for the 3 nacelles tested

\begin{tabular}{ccccc}
\hline & Nacelle 1 & Nacelle 2 & Nacelle 3 sideline & Nacelle 4 \\
\hline $\mathrm{d}_{\mathrm{m}} / \mathrm{d}_{\mathrm{i}}$ & 1.176 & 1.237 & 1.220 & 1.308 \\
$\mathrm{~L}_{\mathrm{t}} / \mathrm{d}_{\mathrm{i}}$ & 3.367 & 1.840 & 1.816 & 2.151 \\
$\mathrm{~L}_{\mathrm{f}} / \mathrm{L}_{\mathrm{t}}$ & 0.16 & 0.41 & 0.36 & 0.40 \\
$\mathrm{R}_{\mathrm{if}} / \mathrm{d}_{\mathrm{i}}$ & 0.0517 & 0.0242 & 0.0343 & 0.0280 \\
\hline
\end{tabular}

The first three of these geometries (Nacelle 1,2,3) were previously tested at ARA in the transonic wind tunnel [16] [28] [29]. Nacelle 1 was tested experimentally using a sting mounted isolated intake and nacelle [16] across a range of Reynolds number based on maximum diameter from $1.5 \times 10^{6}$ to $2.4 \times 10^{6}$. The nacelle drag was evaluated using a wake integral method for a range of MFCR from 0.3 to 1.0 and, freestream Mach number from 0.4 to 0.95 . Nacelles 2 and 3 were also assessed in the same facility although the measurements were conducted at different periods and consequently the experimental arrangements and the aerodynamic analyses were also slightly different. In particular, nacelle 1 was tested significantly earlier than nacelles 2 and 3 and with a larger rake which would influence the wake integral measurements due to tunnel blockage [16] [28] [29]. Nacelle 2 was tested for a range of MFCR from 0.45 to 0.7 and freestream Mach number from 0.8 to 0.89 for incidences of 0,2 and 4 degrees. The nacelle was tested at a range of

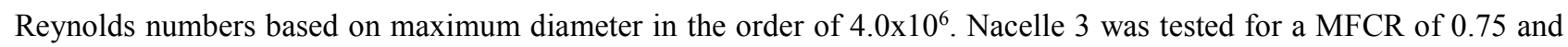
freestream Mach number from 0.8 to 0.88 for incidences of 4 degrees and 6 degrees. The nacelle was tested at a range of Reynolds numbers based on maximum diameter in the order of 4.0x10 .

\section{B. CFD scope and method}

The CFD methodology is considered in two aspects: axisymmetric models for the zero incidence studies and 3D configurations for the incidence studies and non-axisymmetric geometries. Axisymmetric calculations utilised a 2D axisymmetric grid, whereas for cases in which the flow or geometry were non-axisymmetric a 3D half model was used. For 2D axisymmetric computations, a semi-circular domain was generated around the geometries and for the 3D computations a hemi-spherical domain was used. To assess the effect that the sting mount used in the experiments has on the nacelle aerodynamics, geometries were produced to represent the models both with and without the sting (Figure 2a, b). A model with a sting is the closest representation of a wind tunnel configuration and the model without the sting is used to determine the impact of this experimental configuration on the key nacelle metrics. In addition a mesh was created for a nacelle with an exhaust system (Figure 2c). Multi-block structured meshes were generated with ICEM [32] using the gridding guidelines from the AIAA Drag Prediction Workshop (DPW) [33]. A near wall mesh region was constructed to resolve the boundary layer and to provide $\mathrm{y}^{+}$values in the order of 1 . In the region outside of the boundary layer the maximum cell growth rate of 1.5 was applied in all directions. Within the boundary layer mesh the maximum cell growth normal to the wall was restricted to 1.2. For the purposes of these CFD analyses 14 computational meshes were produced as summarised in Table 2 covering four nacelles in three configurations of a nacelle and sting (NS), a free flying nacelle $(\mathrm{N})$, and a nacelle with an exhaust (NE) (Figure 2). 
Table 2 Summary of CFD meshes (millions of cells)

\begin{tabular}{lcccc}
\hline & Dimensions & $\begin{array}{c}\text { Nacelle with sting } \\
\text { (NS) }\end{array}$ & $\begin{array}{c}\text { Nacelle without } \\
\text { sting (N) }\end{array}$ & $\begin{array}{c}\text { Nacelle with separate jet } \\
\text { exhaust (NE) }\end{array}$ \\
\hline Nacelle 1 & 2D & 0.03 & $N / A$ & $N / A$ \\
Nacelle 2 & 2D & $0.03,0.06,0.11$ & 0.03 & $N / A$ \\
Nacelle 2 & 3D & 6.0 & $3.0,5.9,12.0$ & $N / A$ \\
Nacelle 3 & 3D & 6.6 & 6.4 & $N / A$ \\
Nacelle 4 & 2D & 0.03 & 0.044 & 0.074 \\
\hline
\end{tabular}

(a)

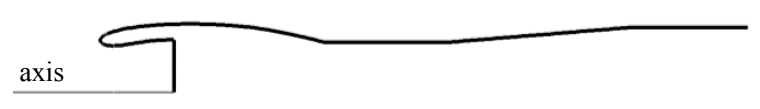

(b)

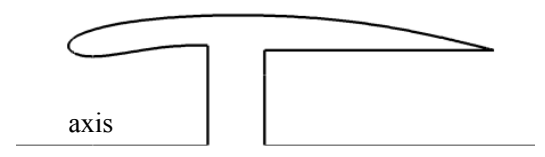

(c)

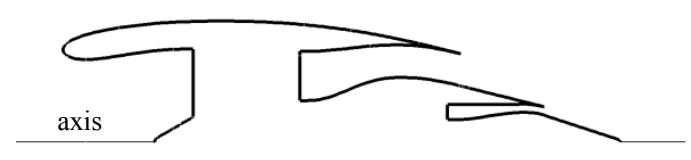

Figure 2 Configurations used in nacelle analyses (a) Nacelle with sting (NS) (b) Free flying nacelle with cylindrical exhaust (N) (c) Free flying nacelle with exhaust system (NE)

The CFD aerodynamic configurations were chosen to represent a wide range of aerodynamic conditions and to capture the effects of drag rise, spillage drag and centreline incidence $\left(\alpha_{C L}\right)$ (Table 3). The Reynolds numbers of the wind tunnel analysis are lower than typical cruise Reynolds number of civil aircraft. For altitudes in the region of 11,000 metres at typical Mach numbers of 0.8-0.85, the Reynolds number would be an order of magnitude higher. To simulate the typical transition behaviour of a full scale nacelle, transition is usually fixed at a particular point using roughness strips. Wind tunnel analyses of nacelles 1 and 2 both had the boundary layer transition fixed with the use of transition strips to be more representative of a nacelle in flight. For nacelle 1, these strips were located at $2 \% \mathrm{~L}_{t}$ aft of the highlight [16]. For nacelle 2 the strips were located at approximately $4 \% \mathrm{~L}_{\mathrm{t}}$ aft of the highlight [28]. All results reported in this paper are from fully turbulent calculations. The Mach number ranges of the CFD were chosen based on the estimated location of the drag rise Mach number from the wind tunnel analysis. Similarly, MFCR ranges were chosen to suitably capture the critical area ratio and subsequent increase in spillage drag. Conditions for nacelle 4 were tested at a comparable range of M and MFCR to the previous nacelles, but to represent a cruise altitude of $10,668 \mathrm{~m}$ a higher Reynolds number is used (Table 3 ).

Table 3 CFD aerodynamic configurations

\begin{tabular}{ccccc}
\hline & $\mathbf{M}_{\infty}$ & MFCR & Re (million) & $\boldsymbol{\alpha}_{C L}\left({ }^{\circ}\right)$ \\
\hline Nacelle 1 & $0.65-0.95$ & $0.4-0.78$ & $2.0-2.2$ & 0 \\
Nacelle 2 & $0.8-0.89$ & $0.45-0.7$ & $4.0-4.5$ & $0-4$ \\
Nacelle 3 & $0.8-0.88$ & $0.55-0.85$ & $4.2-4.4$ & $4-6$ \\
Nacelle 4 & $0.7-0.9$ & $0.55-0.75$ & $4.5-28.9$ & 0 \\
\hline
\end{tabular}


The steady RANS equations were solved for all cases using a double precision implicit density-based solver [32]. The discretisation was second order with a Green-Gauss node based scheme. The turbulence model was the two equation k- $\omega$ SST model which was chosen for the improved boundary layer modelling over the standard k- $\varepsilon$ model. Curvature correction was enabled for the 3D computations due to the improvements in modelling highly curved streamlines [34] which are present in nacelles operating at incidence. Iterative convergence was achieved for normalised residual values of $10^{-5}$. The axial force on the nacelle was monitored for 500 iterations and did not vary more than $0.006 \%$ of the absolute value and was deemed acceptable.

\section{Grid independence study}

The effect of the grid discretisation on the computational results was assessed for the Nacelle 2 configuration for both 2D axisymmetric and 3D configurations. The 2D axisymmetric configurations with the sting were examined at $M_{\infty}=0.8$, $\mathrm{MFCR}=0.7$ and $\mathrm{Re}=4.2 \times 10^{6}$. Using the approach recommended by Roache [35], the grid convergence index (GCI) was calculated for $c_{D *}$ from the nacelle 2 cases based on grids between 30,000 and 110,000 cells. The coarsest mesh was chosen for all further cases, which demonstrated around a 1\% error compared to the Richardson extrapolation from medium to fine of $c_{D *}$.

To assess the grid sensitivity of the 3D meshes a similar study was carried out on nacelle 2 using meshes of $3.0,6.0$ and 12.0 million cells. For the case at $\alpha_{C L}=0, \mathrm{M}_{\infty}=0.8$ and MFCR $=0.7$, the $c_{D *}$ showed a monotonic increase from the coarse to the fine mesh with a variation of $1 \%$. The medium mesh was therefore decided to be in the solution asymptotic range and consequently the medium mesh of 6 million cells was chosen for all subsequent computations.

\section{Domain independence study}

A domain independence study was carried out for nacelle 2 in the $2 \mathrm{D}$ axisymmetric configuration. Domain diameters of $60 d_{m}, 80 d_{m}$, and $100 d_{m}$ were tested. For the case of $M_{\infty}=0.8, M F C R=0.7$ and $\alpha_{C L}=0$ tested without the sting, the difference in modified drag coefficient was $\Delta c_{D *}=6 \times 10^{-5}$ between the medium and large domain. This is approximately $0.2 \%$ of the nominal $c_{D *}$ for this configuration and therefore the medium domain with domain diameter of $80 d_{m}$ was chosen for further calculations. The same diameter was used for the hemi-sphere diameter domain for the 3D cases.

\section{Drag extraction}

There are many methods of extracting drag from a CFD solution which are split broadly into far field methods and near field methods [36]. Both of these approaches aim to exclude spurious drag as far as possible. Near field drag extraction methods are based on the integration of the forces acting on the nacelle tangential to the flow direction and can formally be defined by equation 3 [36]. The first term in the brackets (equation 3) describes the pressure force acting on the nacelle whilst the other three terms are the viscous forces. The pressure term includes drag contributions from shock waves and boundary layer displacement effects making it impossible to separate these influences in a nearfield method. The other problem with a near field formulation is the reliance on mesh density and turbulence model to ensure adequate resolution in the pressure integration and to avoid numerical dissipation leading to spurious drag [37]. Conversely, far field methods determine drag through surface integration of a control volume surrounding the object and flow of interest. It is assumed 
for these methods that the control volume contains all viscous and wave drag effects and that the momentum loss measured at the surfaces is caused by these. The wake integral method is a form of far field drag extraction where the drag is calculated based on the losses measured in a downstream wake. The integral (equation 4) is evaluated at nominal downstream infinity plane, which for practical reasons is taken at a point at which there are no further total pressure losses. This method requires for the wake to be split into regions of area (A) where the local mass flow rate $(\dot{m})$ is known and the local flow velocity (V) can be measured.

$$
\begin{aligned}
& D=\iint_{S_{\text {Body }}}\left(-p n_{x}+\tau_{x x} n_{x}+\tau_{x y} n_{y}+\tau_{x z} n_{z}\right) d S \\
& D=\int \dot{m}\left(V_{\infty}-V\right) d A
\end{aligned}
$$

In the wind tunnel experiments [16] [28] [29], a rake was used to measure a plane downstream of the nacelle to assess the momentum loss throughout the wake plane, providing discrete measurements of total and static pressures. Values for experimental uncertainty were not provided in the experimental reports. The experimental equipment provided 26 pressure readings at 4 azimuthal positions for nacelle 1 to assess the wake losses [16]. From the CFD solution it was estimated that this accounted for between three and four measurements within the boundary layer for the range of Mach numbers tested. For nacelles 2 and 3, the rake had a greater spatial resolution of probes near the surface of the sting so this number of measurement points was estimated to be between five and eight probes [38]. To demonstrate the discretisation accuracy of this method, the wake integral method was performed on a CFD solution at both CFD resolution and rake resolution. The CFD resolution had between 38 and 40 finite volume cells in the wake boundary layer of the nacelle compared to the range of five to eight of the rake in the experiment. The assessment of the CFD based on these different resolutions was then converted into a simulated estimate of the uncertainty based on the original wind tunnel measurements to demonstrate the sensitivity of the wake integral method to measurement resolution. The simulated uncertainty in $\mathrm{C}_{\mathrm{D}}$ increased as freestream Mach number increased, from $\pm 2 \times 10^{-5}$ at $M_{\infty}=0.8$ to $\pm 5 \times 10^{-4}$ at $M_{\infty}=$ 0.89. The uncertainty also depended on the MFCR and varied from $\pm 2 \times 10^{-5}$ at $M F C R=0.7$ to $\pm 3 \times 10^{-5}$ at $M F C R=$ 0.45. This growing error with Mach number has an impact on the ability to correctly determine the drag rise Mach number, particularly when determined by a gradient criterion. The simulated uncertainty on the drag rise Mach number based on equation 1 is $\pm 5 \times 10^{-4}$.

The uncertainty from the wake integral method was notable (between $\pm 2 \times 10^{-4}$ and $\pm 5 \times 10^{-4}$ ) for the Mach numbers of particular interest and the exact experimental procedure could not be thoroughly analysed since it was unknown exactly how many probes were located inside the measured wake. In addition to this, small errors in the estimated free stream velocity can create large errors in drag, due to the summation of the differences in velocity over potentially relatively large areas (equation 4). Therefore, for the CFD analyses drag characteristics were determined using the modified near field method [39]. The modified near field method involves direct integration of the forces which act on the surfaces of the nacelle. It is a near field approach to drag extraction based on integration of the pressure and viscous forces which act on the outer nacelle and a momentum integration of the pre-entry stream tube [39]. Figure 3 shows the basis of the modified near field as the sum of the integrated forces acting on the nacelle $\phi_{\text {nac }}$ and pre-entry streamtube $\phi_{\text {pre }}$. This method was used to calculate the modified nacelle drag $\left(D^{*}{ }_{n a c}\right)$ (equation 5) and reported as modified drag coefficient $\left(c_{D *}\right)$, relative to the maximum nacelle area and free stream conditions (equation 6).

$$
D^{*}{ }_{n a c}=\phi_{n a c}+\phi_{\text {pre }}
$$




$$
c_{D *}=\frac{D^{*} \text { nac }}{\frac{1}{2} \rho_{\infty} V_{\infty}^{2} A_{m}}
$$

However, as the experimental rake is located between 0.12 and 0.7 nacelle lengths downstream of the trailing edge, depending on the rig, some of the measured drag is due to viscous losses incurred by the sting. In these cases an additional drag term acting on the sting $\phi_{\text {sting }}$ must be taken into account. An adjusted drag $\left(D^{\prime}{ }_{n a c}\right)$ is therefore defined which gives the value assessed at the location of the experimental rake, equation 7 , or as a drag coefficient in equation 8 .

$$
\begin{aligned}
& D_{n a c}^{\prime}=\phi_{\text {nac }}+\phi_{\text {pre }}+\phi_{\text {sting }} \\
& c_{D^{\prime}}=\frac{D^{\prime} \text { nac }}{\frac{1}{2} \rho_{\infty} V_{\infty}^{2} A_{m}}
\end{aligned}
$$

As part of the experimental programme [38] this additional drag term $\left(\phi_{\text {sting }}\right)$ was estimated in the analyses of nacelles 2 and 3 based on flat plate aerodynamic characteristics and subtracted from the measured drag $\left(D^{\prime}{ }_{n a c}\right)$ to produce an estimate of the modified nacelle drag $\left(D^{*}{ }_{n a c}\right)$. For the CFD validation of nacelles 2 and 3, this flat plate method was reproduced to give a corrected drag coefficient $\left(c_{D c}\right)$ (equation 15). As was the case in the wind tunnel analysis a correlation (equation 9) [40] for flat plate skin friction was used to estimate the average skin friction coefficient of the sting section.

$$
c_{f}=\frac{0.455}{\left(\log _{10} R e\right)^{2.58}\left(1+0.144 M^{2}\right)^{0.65}}
$$

Two values of Reynolds number $(R e)$ were calculated for the cowl length $\mathrm{L}_{\mathrm{t}}$ (equation 10) and the cowl and sting length $\mathrm{L}_{\text {sting }}$ combined (equation 11) from the Reynolds number per unit length (Rex).

$$
\begin{aligned}
& R e_{\text {nac }}=\operatorname{Rex} L_{t} \\
& R e_{\text {combined }}=\operatorname{Rex}\left(L_{t}+L_{\text {sting }}\right)
\end{aligned}
$$

Equation 9 then gives the average $\mathrm{C}_{\mathrm{f}, \mathrm{t}}$ for the cowl and $\mathrm{C}_{\mathrm{f} \text {,combined }}$ for the sting and cowl combined. A calculation of the skin friction drag incurred by the sting $\left(\mathrm{C}_{\text {Dsting }}\right)$ is then estimated from the difference of the area weighted skin friction for $c_{f, \text { combined }}$ and $\mathrm{C}_{\mathrm{f}, \mathrm{t}}$ (equation 12).

$$
c_{\text {Dsting }}=\left[\frac{A_{w c}+A_{w s}}{A_{\max }}\right] c_{f, \text { combined }}-\frac{A_{w c}}{A_{\max }} c_{f, t}
$$

The experimental data reported for nacelles 2 and 3 had this correction for the sting applied to the measured drag to provide a corrected nacelle drag coefficient $\left(c_{D c}\right)$ (equation 13).

$$
c_{D c}=c_{D \prime}-c_{D s t i n g}
$$

This method is the same as was used in the wind tunnel analyses. The use of a near field method also allows the drag to be suitably decomposed into the drag of the nacelle and the drag of the sting.

For configurations with an exhaust nozzle (NE) also simulated (Nacelle 4) or with a pressure matched exhaust (N) the efflux generates an exit streamtube and there is an additional drag component: the pressure force acting on the exit streamtube $\left(\phi_{\text {post }}\right)$. For the cases with this additional force, the pressure was integrated along a bounding streamline extended from the nacelle trailing edge. This post exit force $\left(\phi_{\text {post }}\right)$ was then incorporated into the standard nacelle drag $\left(D_{n a c}\right)$ (equation 14) and reported as a coefficient based on freestream conditions and maximum nacelle area (equation 15). A post exit force coefficient is also defined (equation 16).

$$
D_{\text {nac }}=\phi_{\text {nac }}+\phi_{\text {pre }}+\phi_{\text {post }}
$$




$$
\begin{aligned}
& C_{D}=\frac{D_{\text {nac }}}{\frac{1}{2} \rho_{\infty} V_{\infty}^{2} A_{m}} \\
& c_{D, p o s t}=\frac{\phi_{\text {post }}}{\frac{1}{2} \rho_{\infty} V_{\infty}^{2} A_{m}}
\end{aligned}
$$

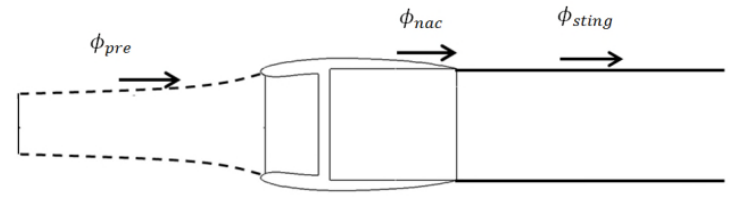

Figure 3 Diagram of the forces which act on an isolated nacelle, sting and streamtube, based on AGARD 237

$$
\text { [41] }
$$

\section{Results}

\section{A. CFD Validation}

\section{2D Axisymmetric results}

Experimental data for nacelle 1 were reported as adjusted nacelle $c_{D}$, values (Equation 8), which include the viscous drag of $0.12 L_{t}$ of cylindrical sting section downstream of the nacelle trailing edge. CFD analyses were carried out with the medium domain and coarse mesh for nacelle 1 with the sting (NS) for a range of Mach numbers from 0.65 to 0.95 . The adjusted drag coefficient $c_{D}$, predicted by the CFD was typically within $4 \%$ of the experimental data prior to drag rise (Figure $4 \mathrm{a}, \mathrm{b}, \mathrm{c}$ ). The CFD accuracy for $\mathrm{M}_{\mathrm{DR}}$, using equation 1, was between $\Delta \mathrm{M}_{\mathrm{DR}}=-0.001$ for $\mathrm{MFCR}=0.6$ and $\Delta \mathrm{M}_{\mathrm{DR}}=-$ 0.014 for $\mathrm{MFCR}=0.76$ (Table 4). The CFD simulations slightly under-predicted the influence of the spillage drag measured at lower MFCRs (Figure 4d). For example, the measured $c_{D}$, increased from 0.036 to 0.064 when the MFCR was reduced from 0.78 to 0.51 at $\mathrm{M}=0.85$ to give $\Delta c_{D^{\prime}}=0.028$. Across the same range of MFCR the CFD calculated $\Delta c_{D^{\prime}}=0.02$. The $\mathrm{M}_{\mathrm{DR}}$ for both the experiment and the CFD data show that with a lower MFCR, the drag increase occurs at a lower Mach number (Table 4). This is caused by the local incidence of the flow increasing at the highlight for a lower MFCR. A lower MFCR causes the stagnation point on the nacelle to move closer to the throat and therefore the flow has a greater distance to travel around the lip. Since this region is highly curved a large acceleration occurs which gives a higher peak Mach number and results in a stronger shock.

Table 4 Measured and CFD predicted drag rise Mach number for nacelle 1

\begin{tabular}{ccc}
\hline MFCR & $\begin{array}{c}\text { CFD } \\
\left.\boldsymbol{M}\right|_{\frac{\partial c_{D^{\prime}}}{\partial M_{\infty}}=\mathbf{0 . 1}}\end{array}$ & $\begin{array}{c}\text { Measurement } \\
\left.\boldsymbol{M}\right|_{\frac{\partial c_{D^{\prime}}}{\partial M_{\infty}}=\mathbf{0 . 1}}\end{array}$ \\
\hline $\mathbf{0 . 6}$ & 0.825 & 0.826 \\
$\mathbf{0 . 7}$ & 0.845 & 0.848 \\
$\mathbf{0 . 7 6}$ & 0.852 & 0.866 \\
\hline
\end{tabular}




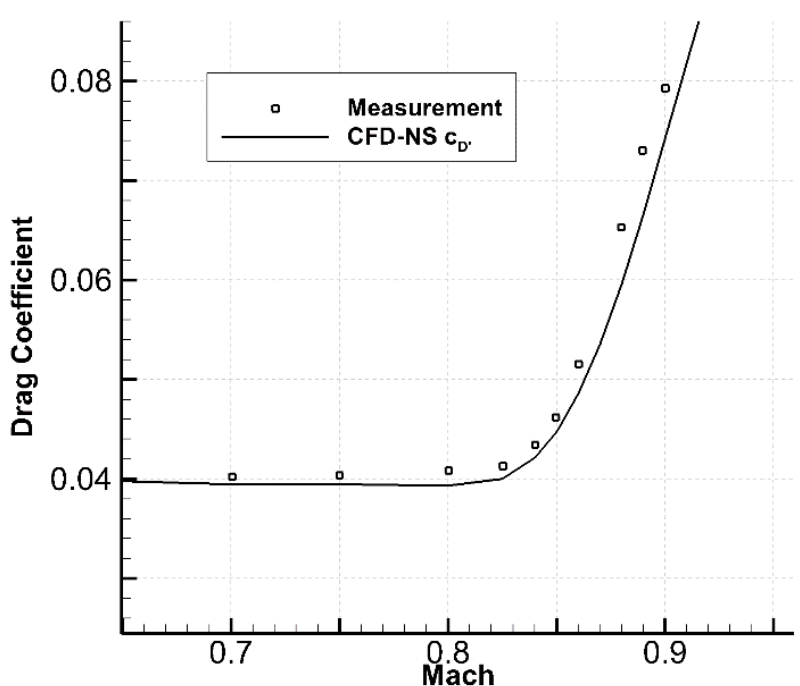

(a) $\mathrm{MFCR}=0.6$

(c) $\mathrm{MFCR}=0.76$

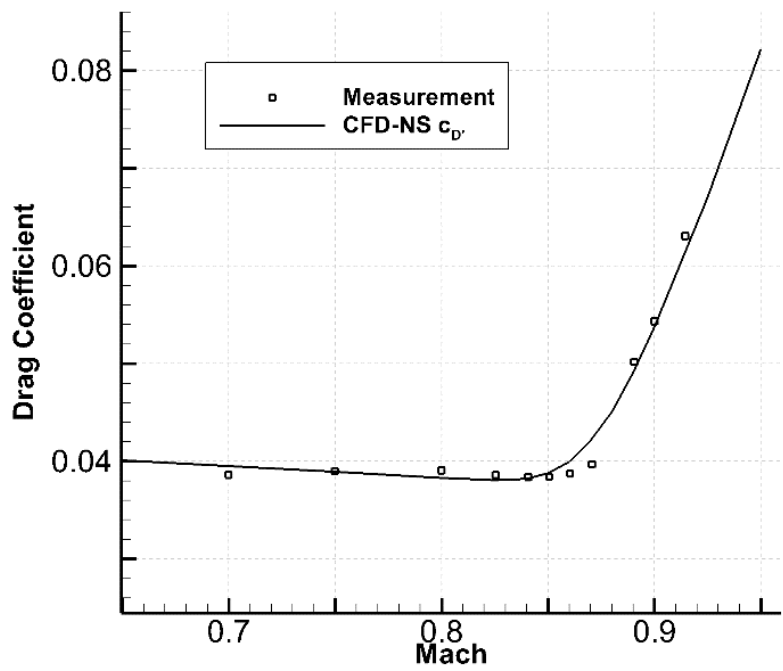

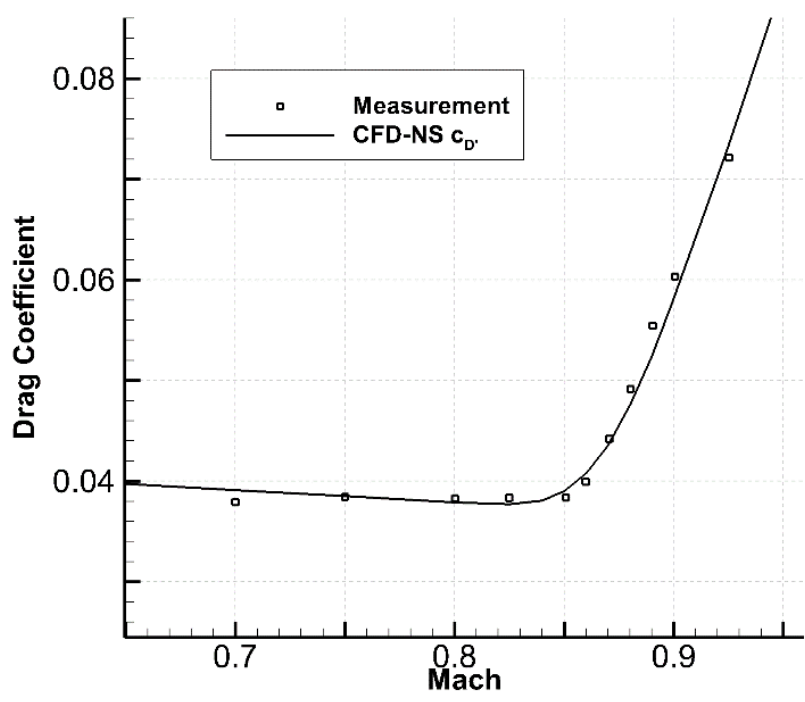

(b) $\mathrm{MFCR}=0.7$

(d) $\mathrm{M}_{\infty}=0.85$

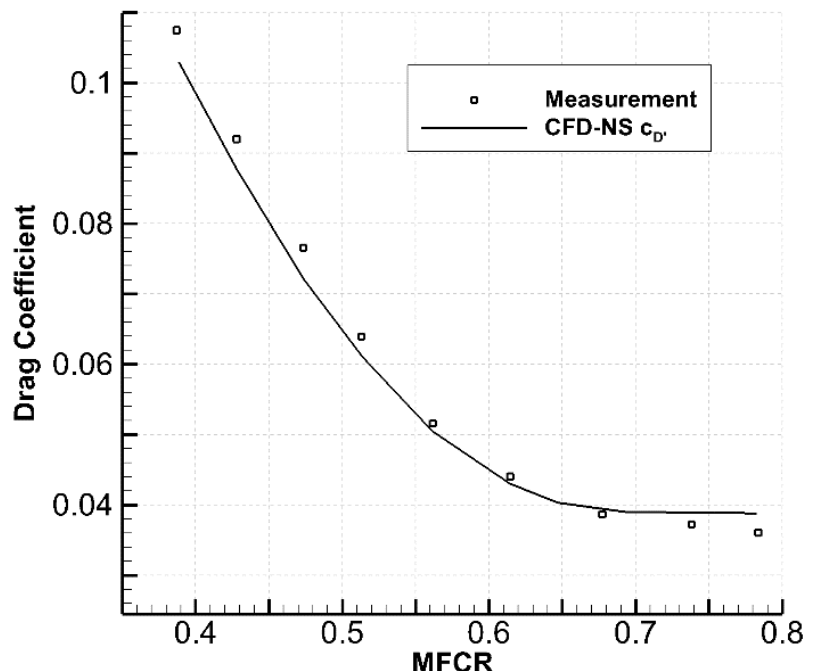

Figure 4 Drag coefficient $\left(c_{D^{\prime}}\right)$ as a function of freestream Mach number for nacelle 1 in the nacelle/sting configuration (NS) for CFD analysis and experimental data [16] at (a) MFCR=0.6, (b) MFCR=0.7, (c) $\operatorname{MFCR}=0.76$, (d) Drag coefficient as a function of MFCR at $M_{\infty}=0.85$ 
(a)

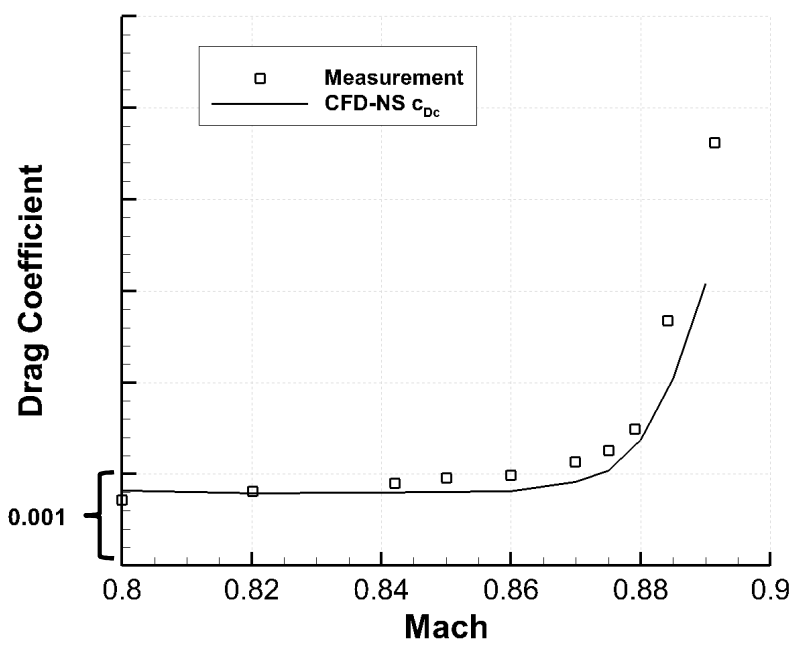

(b)

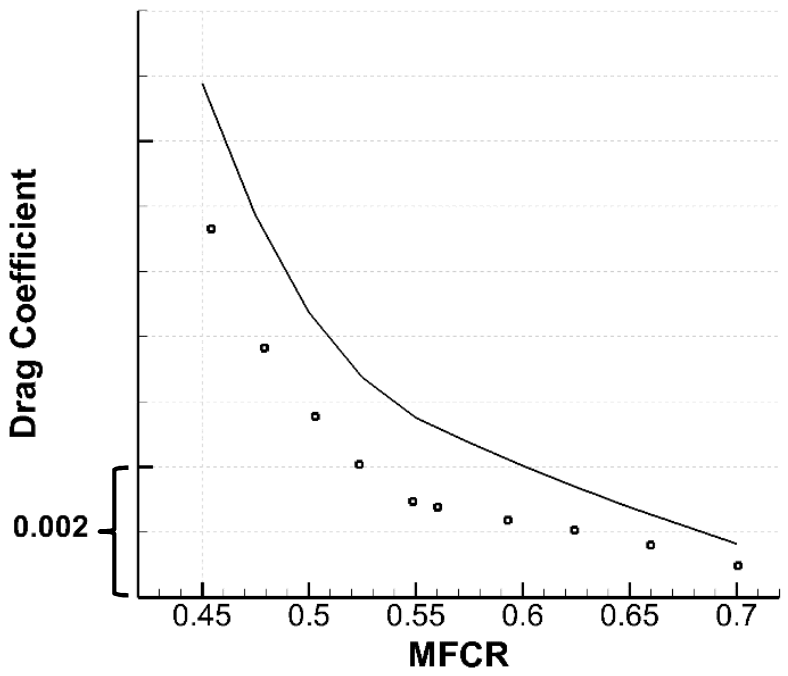

Figure 5 Drag coefficient $\left(c_{D c}\right)$ for nacelle 2 (NS) for CFD analysis and experimental data [28] . (a) $c_{D c}$ as a function of freestream Mach number at MFCR $=0.7$, (b) $c_{D c}$ as a function of MFCR at $M \infty=0.8$

Nacelle 2 was also tested in a sting mounted configuration in the wind tunnel experiments [28]. Due to the placement of the rake downstream of the nacelle trailing edge, some of the measured momentum loss arises from the skin friction which acts on the sting. This should not be included in the nacelle drag and it was corrected for in the wind tunnel experiments by the assumption of a flat plate skin friction correction factor which has been applied to the reported measurements [38]. To reproduce this correction in the current computational work a method based on both the flat plate Reynolds number and Mach number was used to estimate the skin friction caused by the sting as was the case in the experimental procedure [38]. Nacelle 2 therefore was modelled computationally with the sting attached (NS) to give an accurate representation of the experimental set up (Figure 5). The CFD data was also post-processed in the same way as the experimental data (equations 9-13) to determine the corrected drag coefficient $\left(c_{D c}\right)$.

Nacelle 2 is a configuration which was generated using an inverse design approach and is a more modern design compared to nacelle 1. One of the benefits of this design is that, relative to nacelle 1 (Figure $4 \mathrm{~b}$ ), there is a notable increase in the measured $M_{D R}$ from 0.845 to 0.880 at a reference MFCR of 0.7 . Another benefit of this detailed design is the improved performance at lower MFCR (Figure 6). This lower gradient of drag coefficient with MFCR makes the nacelle less penalising in the portions of a flight where a lower power setting is used. The improved control over the curvatures in nacelle 2 resulted in a modest 20\% increase in drag between MFCR 0.7 and MFCR 0.5 compared to an $85 \%$ increase for nacelle 1. At a MFCR of 0.7 , and below the $M_{D R}$ of 0.880 , the CFD predicts the corrected drag coefficient $c_{D c}$ with an RMS $\Delta c_{D c}$ of 0.0001 (Figure 5a). Above the $M_{D R}$ the difference increases and at the highest $\mathrm{M}_{\infty}$ of 0.89 with MFCR of 0.7 , this $\Delta c_{D c}$ is -0.0015 although there is also notable uncertainty in the experimental data at these higher Mach numbers. At this same MFCR of 0.7, the measured $M_{D R}$, was 0.879 and the CFD predicted 0.880 . For the effect of spillage across the range of MFCR from 0.7 to 0.45 at $\mathrm{M}_{\infty}=0.8$, the difference between the CFD and the measurements is an RMS $\Delta c_{D c}$ of 0.0013. The calculated CFD $\Delta c_{D c}$ between $\mathrm{MFCR}=0.7$ and $\mathrm{MFCR}=0.5$ is 0.0036 in comparison with the measured value of 0.0023 . 


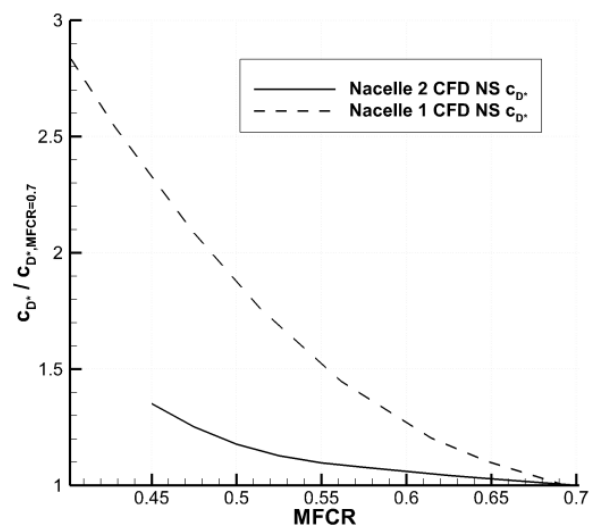

Figure 6 Normalised drag coefficient $\left(c_{D}\right)$ for nacelle 1 and nacelle 2 CFD data as a function of MFCR

\section{Influence of incidence on drag coefficient}

Across the flight envelope, the nacelles will operate at different angles of attack and nacelle 2 and nacelle 3 were investigated at a range of incidence up to $6^{\circ}$. Since it has been demonstrated that the absolute values from the experimental data can be largely influenced by the spatial discretisation of the rake, the analysis centred on the characteristics of drag rise and nacelle Mach number distributions at incidence. Nacelle incidence causes the stagnation of the streamtube to move into the intake near the top surface of the nacelle and further onto the outside of the nacelle lower surface. The influence of nacelle drag is then more pronounced on the topline. The topline streamline must curve more due to the relocation of the stagnation point on the nacelle which causes greater accelerations as well as greater shock strength in supercritical designs. This then causes a change in the drag rise Mach number. In comparison with the measured data (Table 5), the predicted drag rise Mach number from the CFD was in good agreement with differences in $M_{D R}$ of $\Delta \mathrm{M}_{\mathrm{DR}}=0.001$ at 0 degrees to $\Delta \mathrm{M}=0.002$ at 4 degrees for nacelle 2 . The local aerodynamics demonstrates the same flow features for the incidence cases between the CFD and the experiment (Figure 7). The calculated peak isentropic Mach number is within $\Delta \mathrm{M}_{\mathrm{DR}}=0.01$ for nacelle 2 . The relative increase in peak Mach number between 2 and 4 degrees was $\Delta \mathrm{M}=0.122$ for the measurement data and $\Delta \mathrm{M}=0.108$ for the CFD data. The measurement data for nacelle 2 predicts very little change in the drag gradients (Figure $8 \mathrm{a}$ ) between 0 and 2 degrees; for an axisymmetric nacelle a more pronounced change would be expected and is seen in the CFD data (Figure 8a). However, at 4 degrees, the measured impact of incidence is more prominent in the un-drooped configuration, nacelle 2 (Figure 8) with the measured $\mathrm{M}_{\mathrm{DR}}$ decreased by 0.005 to $\mathrm{M}_{\mathrm{DR}}=0.874$ due to a $2^{\circ}$ increase in incidence compared with 0.001 for nacelle 3 (Table 5). There is less impact on the drag rise from incidence for the drooped nacelle (nacelle 3 ), since the drag is a function of the intake incidence as opposed to the quoted centreline incidence. The use of droop is to allow a nacelle to operate in a range of low incidence common in aircraft due to cruise incidence, engine installation and wing upwash. For nacelle 3 , the calculated drag rise Mach number from the CFD was greater by between $\Delta \mathrm{M}_{\mathrm{DR}}=0.007$ at 4 degrees to $\Delta \mathrm{M}_{\mathrm{DR}}=0.003$ at 6 degrees relative to the measured values (Table 5). This modest difference is because the CFD tends to slightly under-predict the severity of the post drag rise drag values with a consistent offset after the drag rise Mach number (Figure 8b). 
Table 5 Measured and CFD predicted drag rise Mach number for nacelle 2 and 3

\begin{tabular}{ccccc}
\hline $\begin{array}{c}\text { Incidence } \\
\left.\mathbf{(}^{\circ}\right)\end{array}$ & \multicolumn{3}{c}{ Nacelle 2 } & \multicolumn{2}{c}{ Nacelle 3 } \\
\cline { 2 - 5 } & CFD & Measurement & CFD & Measurement \\
& $\left.M\right|_{\frac{\partial C_{D C}}{\partial M_{\infty}}=0.1}$ & $\left.M\right|_{\frac{\partial C_{D C}}{\partial M_{\infty}}=0.1}$ & $\left.M\right|_{\frac{\partial C_{D C}}{\partial M_{\infty}}=0.1}$ & $\left.M\right|_{\frac{\partial C_{D C}}{\partial M_{\infty}}=0.1}$ \\
\hline $\mathbf{0}$ & 0.880 & 0.879 & $N / A$ & $N / A$ \\
$\mathbf{2}$ & 0.877 & 0.877 & $N / A$ & $N / A$ \\
$\mathbf{4}$ & 0.874 & 0.872 & 0.866 & 0.859 \\
$\mathbf{6}$ & $N / A$ & $N / A$ & 0.863 & 0.860 \\
\hline
\end{tabular}

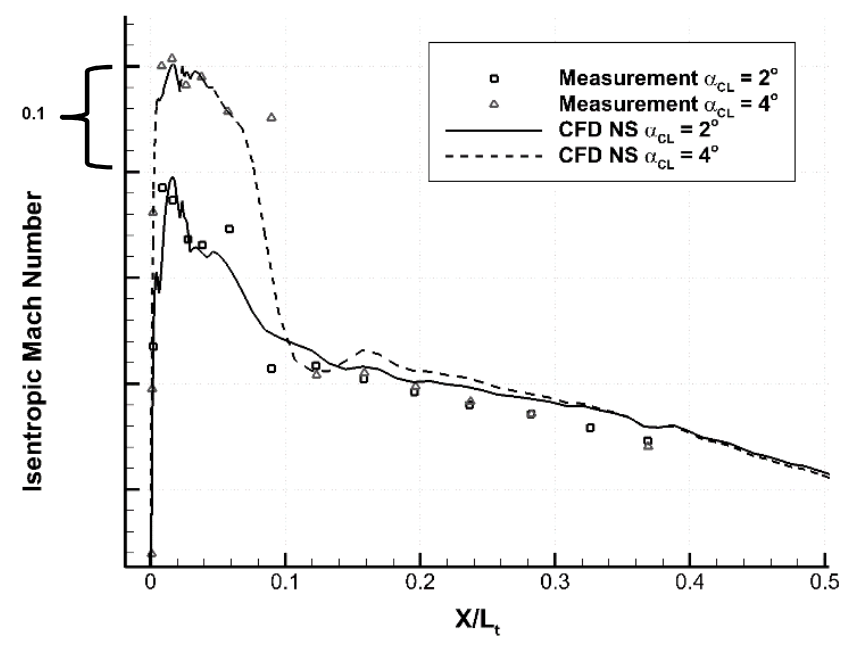

Figure 7 Isentropic Mach distributions over the front 50\% of the nacelle topline for nacelle 2 at $\mathrm{M=0.8}$ at $\boldsymbol{\alpha}_{\mathrm{CL}}=$ $2^{\circ}$ and at $\alpha_{\mathrm{CL}}=4^{\circ}$ 
(a)

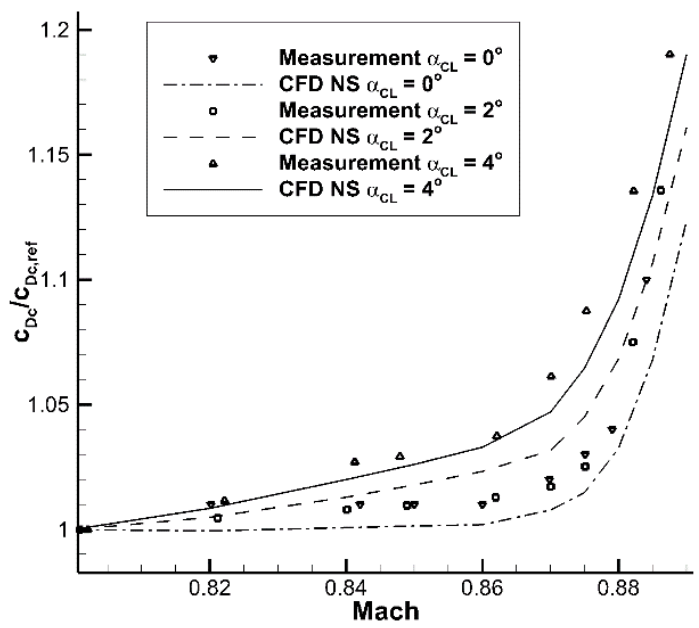

(b)

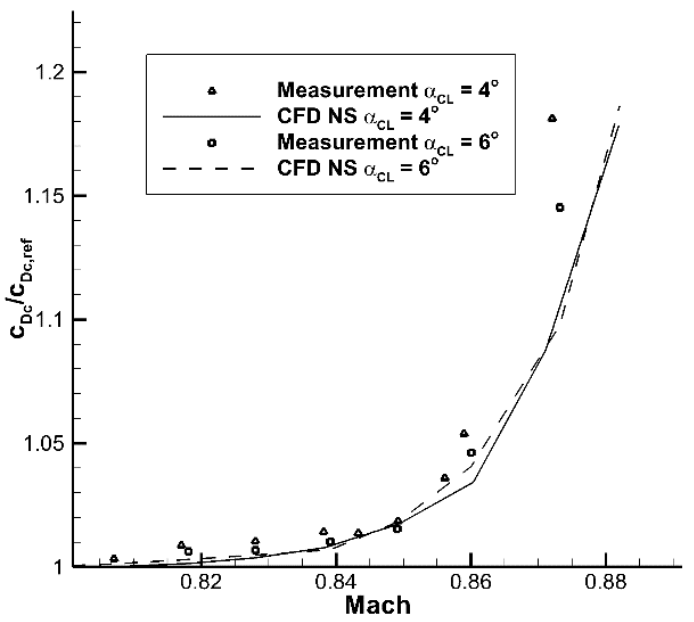

Figure 8 Effect of incidence on drag rise, normalised against drag at $\mathrm{M}=0.8$ for (a) nacelle 2 at MFCR=0.7 and (b) nacelle 3 at $\mathrm{MFCR}=\mathbf{0 . 7 5}$

\section{B. Influence of trailing edge condition}

The purpose of the wind tunnel analysis is to help determine the performance of an engine nacelle in flight. However, the typical requirement for a mounting sting and the absence of the nozzle efflux means that there are differences between the wind tunnel simulation and the flight conditions. To assess the contributions to the overall nacelle drag $\left(c_{D}\right)$ from different configurations and to determine how effectively simple configurations can be used to estimate this drag, two sets of analyses were performed. The first set of computations were performed at wind tunnel model scale (MS) and included nacelle/sting (NS) (Figure 2a), nacelle with a cylindrical nozzle (N) (Figure 2b) and a nacelle with a freestream total pressure matched dual stream exhaust (NE)(Figure 2c). The cylindrical nozzle model was intended to represent the simplest reference condition of a nacelle without a jet, and in order to minimise post exit drag terms, the freestream total pressure and temperature were imposed in the cylindrical nozzle duct. The second set sought to model the engine at altitude and included two different configurations of nacelle with dual stream exhaust (NE). One configuration had efflux matched to the freestream total conditions (PM) and one had the boundary conditions representative of an UHBPR at altitude (RE). The wind tunnel model scale (MS) data was computed with a constant free stream total pressure and total temperature which gave a Reynolds number range based on nacelle maximum diameter of $4.5 \times 10^{6}$ to $5.0 \times 10^{6}$. Based on the International Standard Atmosphere conditions for 10,668m altitude the full scale Reynolds number range was $22.8 \times 10^{6}$ to $29.6 \times 10^{6}$. For the configuration with an exhaust geometry and representative efflux (RE) the nozzle pressure ratios were varied with the engine cycle across the Mach number range to ensure a constant MFCR. The fan nozzle pressure ratio ranged between 1.77 and 2.36 whilst the core nozzle pressure ratio varied between 1.37 and 2.00 between $\mathrm{M}_{\infty}=0.7$ and $\mathrm{M}_{\infty}=0.9$. The cruise condition for this engine is at $\mathrm{M}_{\infty}=0.82$ and MFCR $=0.75$. The effect of the engine power setting is also of interest therefore the influence of MFCR was also assessed for these configurations (Table $6)$. 


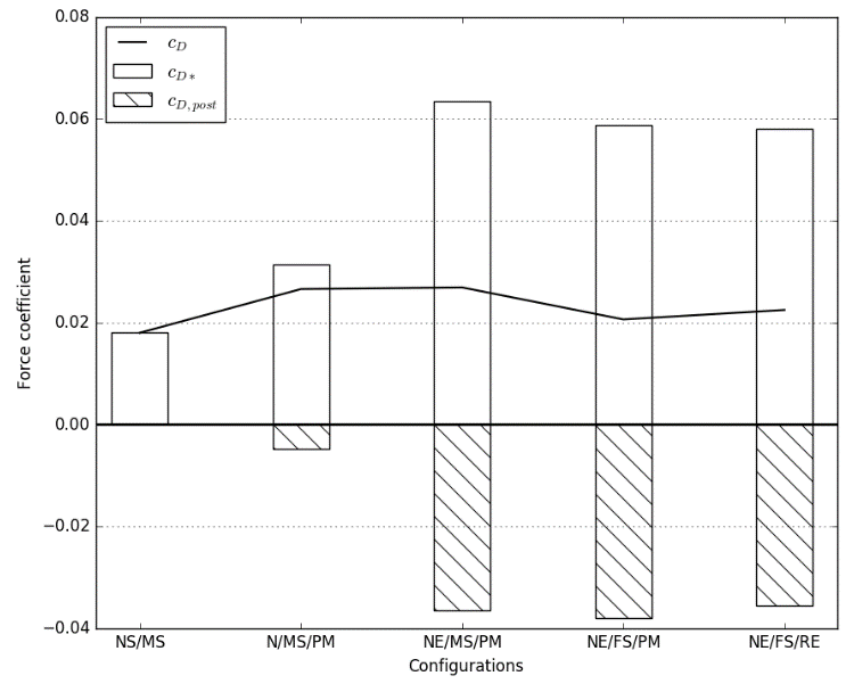

Figure 9 Drag decomposition for CFD results from five configurations of nacelle 4 at $M=0.82$, $M F C R=0.75$, $\alpha_{C L}=\mathbf{0}$

M: $\quad 0.10 .20 .30 .40 .50 .60 .70 .80 .91$

(a)

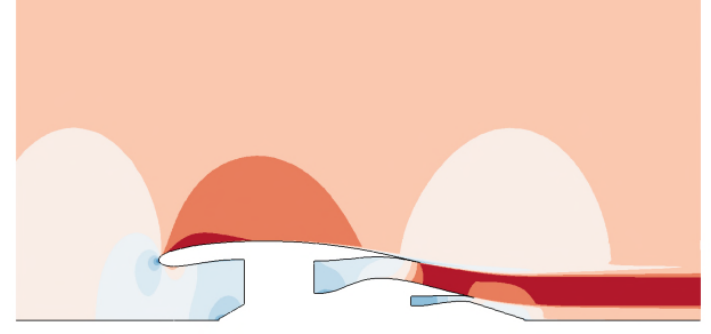

Mach increment: $\quad-0.05-0.04 \quad-0.03-0.02-0.01 \quad 0 \quad 0.01 \quad 0.02 \quad 0.03 \quad 0.04 \quad 0.05$

(c)

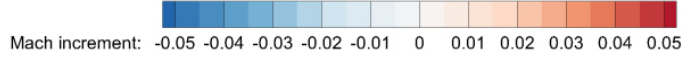

(b)

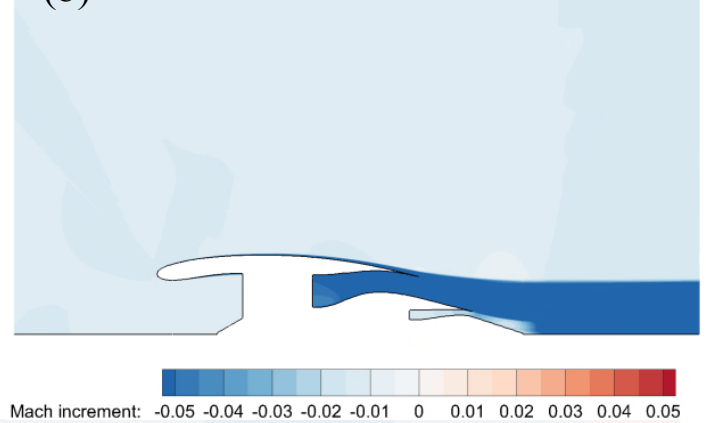

(d)
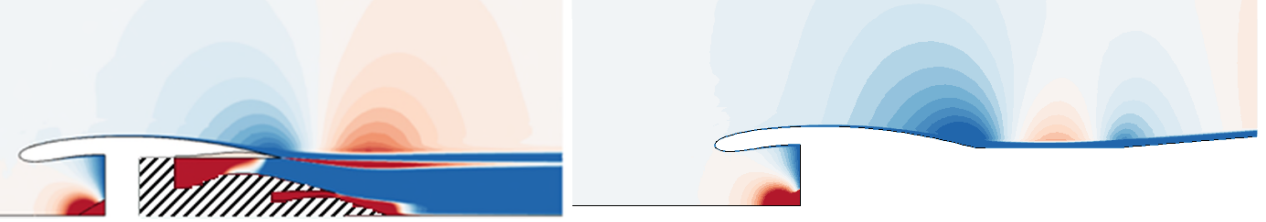

Figure 10 (a) Mach contours for Nacelle 4 (NE/FS/RE) at $M=0.82, M F C R=0.75, \alpha_{C L}=0$ and differences from this configuration to: (b) Nacelle 4 (NE/MS/PM), (c) Nacelle 4 (N/MS/PM), (d) Nacelle 4 (NS/MS)

The cruise drag, assessed at $\mathrm{M}=0.82, \mathrm{MFCR}=0.75$, demonstrates the large discrepancies between the different configurations. The post exit force is an important contributor to the overall drag which is around $61 \%$ of the magnitude of the modified drag (Figure 9) for the NE/FS/RE case. In the configuration with a cylindrical exhaust (N/MS/PM), the post exit terms were predictably much smaller however still reduced the drag by $15 \%$ relative to the modified drag (Figure 9). The sting mounted configuration (NS/MS) gave the lowest overall drag (Figure 9). The predicted value was around 
$20 \%$ lower than the full configuration (NS/FS/RE) (Figure 9). The source of this lower drag can be identified within the flowfield (Figure 10) as an increase in pressure caused by the sting blockage. Locally, the streamlines are turned by both the sting and the boundary layer growth over it which results in a higher relative pressure exerted on the afterbody of the nacelle compared to the configurations without the sting. Relative to the case with the sting (NS/MS), the case with a simple exhaust (N/MS/PM) predicts a 48\% higher cruise drag (Figure 9). This gives a direct quantification of the additional force generated by this streamline turning. The inclusion of the cycle efflux (NE/FS/RE) relative to a pressure matched equivalent (NE/FS/PM) results in a $9 \%$ increase in the measured drag which is partly caused by a change in the post exit force but also in the modified drag as a result of the trailing edge pressure (Figure 10). These comparisons demonstrate that the post exit force has a large influence on the predicted drag and must be accounted for even when an idealised jet is simulated. In addition, the sting mounted nacelle should be treated with caution unless the additional pressure force acting on the afterbody is accounted for and the drag increased accordingly.

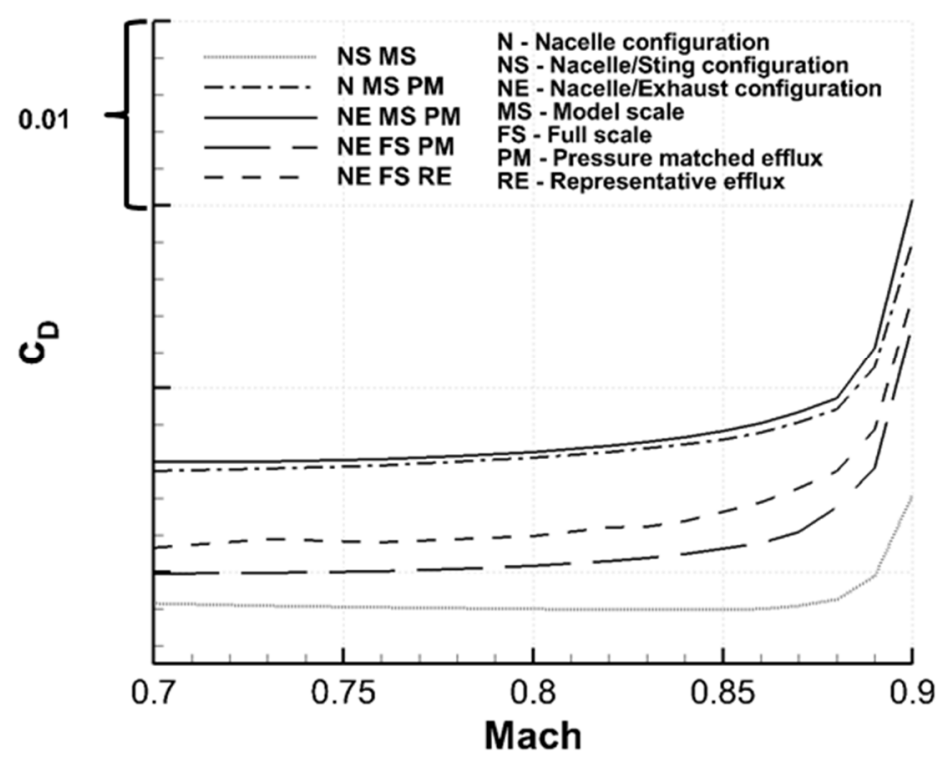

Figure 11 CFD results for nacelle 4 in different configurations evaluated in terms of nacelle drag coefficient $\left(c_{D}\right)$ as a function of $M_{\infty}$ at constant $M F C R=0.75, \alpha_{C L}=0$

Table 6 Drag rise Mach number for different configurations of nacelle 4

\begin{tabular}{rcc}
\hline & $\left.\boldsymbol{M}\right|_{\frac{\partial \boldsymbol{c}_{\boldsymbol{D} *}}{\boldsymbol{\partial} \boldsymbol{M}_{\infty}}=\mathbf{0 . 1}}$ & $\left.\boldsymbol{M}\right|_{\frac{\partial \boldsymbol{c}_{\boldsymbol{D}}}{\boldsymbol{\partial} \boldsymbol{M}_{\infty}}=\mathbf{0 . 1}}$ \\
\hline Nacelle/sting model scale (NS/MS) & 0.882 & N/A \\
Nacelle model scale (N/MS/PM) & 0.877 & 0.877 \\
Nacelle/exhaust model scale (NE/MS/PM) & 0.850 & 0.876 \\
Nacelle/exhaust full scale (NE/FS/PM) & 0.855 & 0.870 \\
Nacelle/exhaust full scale with efflux (NE/FS/RE) & 0.849 & 0.875 \\
\hline
\end{tabular}

The different configurations were also modelled across a range of Mach numbers and the results indicated that the configuration influenced the predicted trends in drag relative to the Mach number (Figure 11). This resulted in different values of drag rise Mach number for the different configurations (Table 6). The model with the sting (NS/MS) once again 
gave the most optimistic prediction, with a $\Delta M_{D R}=0.007$ higher drag rise Mach number than the full (NE/FS/RE) configuration. Drag rise predicted from a model with a sting will again be influenced by the buoyancy provided by the sting presence and should be treated cautiously. Table 6 however demonstrates that the inclusion of the post exit force is only influential on the configurations which include a non-cylindrical exit streamtube. For the full configuration $(\mathrm{NE} / \mathrm{FS} / \mathrm{RE})$ the omission of this term $\left(\phi_{\text {post }}\right)$ results in an under-predicted drag rise by $\Delta M_{D R}=-0.026$. Consequently, it is important to include this value as it can have a large influence on the predicted $M_{D R}$ for designs with an exhaust system.

A spillage increment was calculated between $\mathrm{M}=0.82, \mathrm{MFCR}=0.55$ and $\mathrm{M}=0.82, \mathrm{MFCR}=0.75$ which was defined for both the modified nacelle drag $\left(c_{D *}\right)$ (Equation 17) and the nacelle drag $\left(c_{D}\right)$ (Equation 18). The difference between the two metrics is therefore the change in the force on the post exit streamtube due to the change in the mass flow $\left(\phi_{\text {post }, \text { spill }}\right)($ Equation 19).

$$
\begin{aligned}
& c_{D * \text { spill }}=\left.c_{D *}\right|_{M F C R=0.55}-\left.c_{D *}\right|_{M F C R=0.75} \\
& c_{D \text { spill }}=\left.c_{D}\right|_{M F C R=0.55}-\left.c_{D}\right|_{M F C R=0.75} \\
& c_{D, \text { post }, \text { spill }}=\left.c_{D, \text { post }}\right|_{M F C R=0.55}-\left.c_{D, \text { post }}\right|_{M F C R=0.75}
\end{aligned}
$$

There was a large difference in the spillage drag predicted by the simulation of different configurations (Figure 12). The change in exhaust configuration changed both the size of the post exit force $\left(\phi_{\text {post,spill }}\right)$ and the modified spillage drag $\left(c_{D * \text { spill }}\right)$. The influence of the trailing edge condition therefore influences both the exit streamtube and the forebody spillage. This resulted in the sting mounted (NS/MS) and the nacelle with cylindrical exhaust (N/MS/PM) simulations to predict the highest spillage drags. Conversely, the full configuration (NE/FS/RE) was seemingly affected by a greater modified spillage drag $\left(c_{D * \text { spill }}\right)$ but once the post exit terms were included a negative overall spillage drag was predicted. This is a result of the different shaped streamtube for the lower MFCR with the representative efflux. As the mass flow is reduced the nozzle pressure ratio is also reduced which results in more jet expansion. For this case, the beneficial forward force acting from this offsets any forebody spillage drag and gives a net improvement. To assess the system performance at a lower mass flow the full drag should be considered.

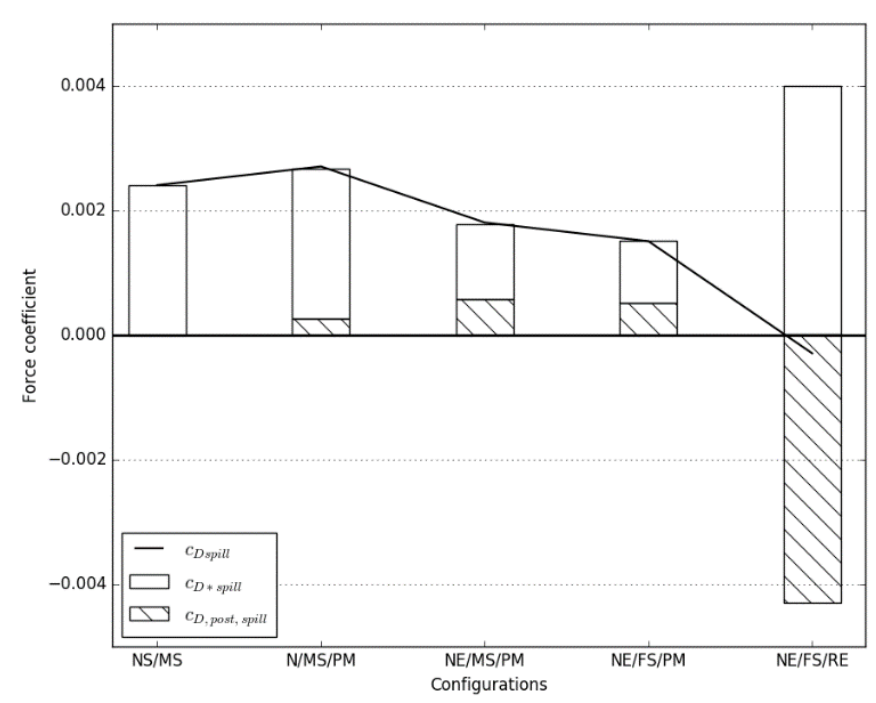

Figure 12 Spillage drag decomposition for CFD results from five configurations of nacelle 4 at $\mathrm{M}=\mathbf{0 . 8 2}$, $\operatorname{MFCR}=0.75, \alpha_{C L}=0$ 


\section{Conclusions}

Various aspects of the characteristics and evaluation of aero-engine nacelle drag have been assessed. A quantitative assessment of the drag components which arise in nacelle wind tunnel tests has been detailed through CFD analyses. The computations have shown reasonable agreement with the measured nacelle drag characteristics for a range of axisymmetric and 3D nacelles. Pre-drag rise nacelle drag is typically determined within 4\% and drag rise Mach number $\left(M_{D R}\right)$ within $\Delta \mathrm{M}_{\mathrm{DR}}=0.003$ at a typical mass flow capture ratio of 0.70 . It has been observed that the experimental and computational modelling of the nacelle exhaust and trailing edge condition can have a notable impact on the drag characteristics.

The use of a sting in experimental work produces an increase in the static pressure at the trailing edge of the nacelle which decreases the measured drag $\left(c_{D \prime}\right)$ and increases the drag rise Mach number $\left(M_{D R}\right)$. Due to a similar effect, the inclusion of an exhaust system with the nacelle, as well as representative efflux flows generating a realistic exit streamtube, greatly increases the modified nacelle drag $\left(c_{D *}\right)$ and significantly lowers the drag rise Mach number $\left(M_{D R}\right)$. Relative to a typical civil aero-engine configuration, with separate jets, the typical wind tunnel configuration of a sting mounted nacelle results in a $\Delta c_{D}=0.0045$ reduction in cruise drag, a $\Delta M_{D R}=0.07$ increase in $M_{D R}$ and a $\Delta c_{D \text { spill }}=0.0027$ increase in the change in spillage drag. Similarly, relative to the separate jets exhaust, the computational modelling approach of using a simple idealized exhaust results in a $\Delta c_{D}=0.0041$ increase in cruise drag, a $\Delta M_{D R}=0.02$ increase in $M_{D R}$ and a $\Delta c_{\text {Dspill }}=0.0030$ increase in the change in spillage drag.

For a configuration with separate jets and a representative exhaust efflux, the post exit terms have a significant impact on the different drag components. The post exit terms are as large as around $60 \%$ of the overall modified drag $\left(c_{D *}\right)$ for the case demonstrated. These terms also affect the $\mathrm{M}_{\mathrm{DR}}$ which was 0.025 lower than that evaluated for the full system. Consequently, for such a configuration, the modified nacelle drag $\left(c_{D *}\right)$ is an inappropriate measure of nacelle drag and the overall drag $\left(c_{D}\right)$ including the post exit terms must be used. For a full system representation including a variable NPR in the efflux, the inclusion of the post exit terms also changes the nature of the spillage drag whereby over a small range the spillage can be dominated by an increase in post exit force resulting in a decrease in drag from a decrease in MFCR.

\section{Acknowledgements}

The lead author of this paper was partially supported by a grant from the Engineering and Physical Sciences Research Council. The authors would like to thank Rolls Royce plc for their support. The authors would also like to thank the Aircraft Research Association for their communications during the project.

\section{References}

1. Advisory Council for Aeronautics Research in Europe. Strategic Research Agenda, 2002

2. Parker R. From blue skies to green skies: engine technology to reduce the climate-change impacts of aviation, Technology Analysis \& Strategic Management, 21(1), 2009, pp. 61-78

3. Daly M, Ed. Jane's Aero-Engines. $28^{\text {th }}$ ed. IHS Global Ltd, Surrey, 2010, p. 64 
4. Hoheisel H. Aerodynamic Aspects of Engine-Aircraft Integration of Transport Aircraft, Aerospace Science and Technology, vol. 7, 1997, pp. 475-487

5. Stankowski T. et al. Aerodynamics of aero-engine installation, In: $54^{\text {th }}$ AIAA Applied Aerodynamics Conference, San Diego, California, 2016, AIAA 2016-0764

6. Seddon J. Intake Aerodynamics, $2^{\text {nd }}$ ed., Oxford: Blackwell Science Ltd, 1998, p. 12

7. Daggett DL. et al. Ultra-Efficient Engine Diameter Study, NASA, 2003, NASA Contract Report No. 2003-212309

8. Howe DC., Wynosky T. Energy Efficient Engine Program Advanced Turbofan Nacelle Definition Study, NASA, 1985, NASA Contract Report $1 / 4942$

9. Vassberg JC. Development of a Common Research Model, In: $26^{\text {th }}$ AIAA Applied Aerodynamics Conference, Honolulu, Hawaii, 2008, AIAA 2008-6919

10. Rivers MB. Experimental Investigations of the NASA Common Research Model in the NASA Langley National Transonic Facility and NASA Ames 11-Ft Transonic Wind Tunnel, In: 49 ${ }^{\text {th }}$ AIAA Aerospace Sciences Meeting including the New Horizons Forum and Aerospace Exposition, Orlando, Florida, 2011 AIAA 2011-1126

11. Faust GK., Mungur P. Nacelle Design, NASA Langley Research Center, Research in Natural Laminar Flow and Laminar-Flow Control, Part 3, pp.891-907, 1987

12. Roskam J., Lan C.-T.E. Airplane Aerodynamics and Performance, DARcorporation, Lawrence Kansas, 1997, p. 141

13. Shevell RS., Bayan FP. Development of a method for predicting the drag divergence Mach number and the drag due to compressibility for conventional and supercritical wings, Stanford University, Department of Aeronautics and Astronautics, 1981, Technical Report, SUDAAR-522

14. Borradaile JA. Towards the optimum ducted UHBR engine, In: AIAA/AHS/ASME/ASEE $24^{\text {th }}$ Joint Propulsion Conference, Boston, Massachusetts, 1988, AIAA Paper 1988-2954

15. ESDU. Mass flow and momentum functions for one-dimensional flow of gas in ducts, 1981, ESDU-81004

16. Langley M. The Design of Axisymmetric Cowls for Podded Nacelles for High By-Pass Ratio Turbofan Engines, Aeronautical Research Council, 1979, R\&M no. 3846

17. Farokhi S. Aircraft Propulsion, $1^{\text {st }}$ Ed., Wiley, 2009, p.241

18. Obert E. Aerodynamic Design of Transport Aircraft, $1^{\text {st }}$ Ed., Amsterdam: IOS Press, 2009, pp. 491-492

19. Becker JV. Wind Tunnel Investigation of Air Inlet and Outlet Openings on a Streamline Body, NACA, Langley, Virginia, 1940, NACA-1038

20. Baals DD. et al. The Development and Application of High-Critical-Speed Nose Inlets, NACA, Langley, Virginia, 1945, NACA-920

21. Re R. An Investigation of Several NACA 1-Series Axisymmetric Inlets at Mach Numbers from 0.4 to 1.29, NASA, Hampton, Virginia, 1975, NASA TM X-2917

22. Mullender AJ., Lecordix JL. The ELFIN II and LARA HLF nacelles: Design manufacture and test, In: $2^{\text {nd }}$ European forum on laminar flow technology, Bordeaux, France, 1996

23. Young TM. An investigation into potential fuel savings for 110-130 seat passenger transport aircraft due to the incorporation of natural laminar flow or hybrid laminar flow control on the engine nacelles, Proc IMechE Part G: $J$ Aerospace Engineering, 227(8), 2012, pp. 1300-1324

24. Re R. Experimental Pressure Distributions on Axisymmetric Cowls at Mach Numbers From 0.60 to 0.92, NASA, Hampton, Virginia, 2006, NASA/TM-2006-214313

25. Thornley S. The Spillage of Two Intakes with Sharp Lipped Cylindrical Cowls Measured by the Wake Traverse Method, Aircraft Research Association Limited, 1975, ARA/N/Model test-88 
26. Giles MB., Cummings R.M. Wake Integration for Three-Dimensional Flowfield Computations: Theoretical Development, Journal of Aircraft, 36(2), 1999, pp. 357-365

27. ESDU. Drag of Axisymmetric Cowls at Zero Incidence for Subsonic Mach Numbers, 1981, ESDU-81024

28. Zakrzewski P. Unpublished Internal Report, Rolls-Royce plc., 1998, IAR85059

29. Patella R. Unpublished Internal Report, Rolls-Royce plc., 1994, IAR41132

30. MacMillian L. Development of a Module Type Computer Program for the Calculation of Gas Turbine Off Design Performance, PhD thesis, Department of Power and Propulsion, Cranfield University, 1974

31. Goulos I. et al. Aerodynamic Design of Separate-Jet Exhausts for Future Civil Aero-engines-Part I: Parametric Geometry Definition and Computational Fluid Dynamics Approach, Journal of Engineering for Gas Turbines and Power, Vol. 138, 2016, pp. 1-14

32. ANSYS ICEM CFD, Software Package, Release 15.0., Canonsburg, PA, 2014

33. Vassberg J et al. Summary of the Fourth AIAA CFD Drag Prediction Workshop, AIAA, 2010, AIAA-2010-4547

34. Spalart PR., Shur M. On the Sensitization of Turbulence Models to Rotation and Curvature, Aerospace Science and Technology, 1(5), 1997, pp. 297-302

35. Roache P. Perspective: A Method for Uniform Reporting of Grid Refinement Studies, Journal of Fluids Engineering, 116(3), 1994, pp. 405-413

36. Van Dam C. Recent experience with different methods of drag prediction, Progress in Aerospace Sciences, 35, 1999, pp. $751-798$

37. Vos JB., Sanchi S. DPW4 Results Using Different Grids Including Near-Field/Far-Field Drag Analysis, In: $28 t h$ AIAA Applied Aerodynamics Conference, Chicago, Illinois, 2010.

38. Fry K. Z30/2 Data Reduction Specification, Aircraft Research Association Limited, 1994, AD-94/32

39. Christie R. et al. Aero-engine installation modelling and the impact on overall flight performance, In: Advanced Aero Concepts, Design and Operations, 2014

40. Raymer D. Aircraft Design, A Conceptual Approach, AIAA Education Series, 1992, p. 282

41. Ministry-Industry Drag Analysis Panel (MIDAP) Study Group, Guide to in-flight thrust measurement of turbojets and fan engines, AGARD. 1979, Report AGARD-AG-237, AGARDograph No. 237 
2018-04-02

\title{
Aspects of aero-engine nacelle drag
}

\author{
Robinson, Matthew
}

SAGE

Matthew Robinson, David G MacManus and Christopher Sheaf. Aspects of aero-engine nacelle drag. Proceedings of the Institution of Mechanical Engineers, Part G: Journal of Aerospace Engineering, Volume 233, Issue 5, 2018, pp. 1667-1682

https://doi.org/10.1177/0954410018765574

Downloaded from Cranfield Library Services E-Repository 